\title{
RISO E HORROR: O GÓTICO CÔMICO DE EDWARD GOREY
}

\section{LAUGH AND HORROR: COMIC GOTHIC IN EDWARD GOREY}

\author{
Angelica Micoanski Thomazine ${ }^{1}$
}

\begin{abstract}
RESUMO: Dentre as subdivisões do gótico encontra-se o gótico cômico, que une horror e humor, com criaturas e histórias que se apoiam no gótico, mas que, em vez de medo, resultam em riso e divertimento. Tais características parecem ser recorrentes nas obras de Edward Gorey, autor e ilustrador norte-americano. Portanto, esta pesquisa visa compreender se, e como, o gótico cômico pode ser identificado em duas obras do autor, nas quais as protagonistas são criaturas monstruosas. Esta pesquisa bibliográfica se baseia em estudiosos do gótico e do humor, como Bergson (1983), Propp (1992), Lovecraft (1987) e Horner e Zlosnik (2000). Em síntese, conclui-se que embora as obras apresentem aspectos góticos através dos cenários, da ambientação e das criaturas monstruosas, em vez de suscitar o medo, elas rompem com as expectativas e levam o leitor ao riso, apresentando aspectos do gótico cômico.
\end{abstract}

PALAVRAS-CHAVE: gótico cômico; horror; humor; Edward Gorey

\begin{abstract}
Comic Gothic is a subdivision of Gothic, which connects horror and humor, presenting gothic creatures and stories which entertain and make people laugh instead of feeling frightened. Aspects like those seem to be be found in the Edward Gorey's books, NorthAmerican author and illustrator. Therefore, this paper aims to understand if and how Comic Gothic and be found in two books written by Gorey, which have monstrous creatures as protagonists. This bibliographical research reviews concepts of authors as Bergson (1983), Propp (1992), Lovecraft (1987) and Horner and Zlosnik (2000). Finally, gothic characteristics were found in both stories, in the illustrations and descriptions of scenes and behavior. However, those characteristics do not frighten the reader, since the reader's expectation is confounded and one laughs, instead, which is the main aspect of comic gothic.
\end{abstract}

KEY WORDS: comic gothic, horror, humor, Edward Gorey

\section{Introdução}

Desde a obra The Castle of Otranto, escrita por Horace Walpole em 1764, o gótico tem se reinventado. Conforme nos lembra James Watt (1999), o gênero foi descrito a partir da crítica literária do século $\mathrm{XX}$, quando passou a receber características próprias. No entanto, a

\footnotetext{
${ }^{1}$ Doutora em Estudos da Tradução pela UFSC. Professora do Departamento de Letras Modernas da UFSM.
} 
diversidade de criações que recorrem a elementos góticos, mas que deram origem a textos singularares, torna clara a impossibilidade de delimitar o gênero.

As obras de Edward Gorey (1925-2000) são um exemplo dessa variedade, pois apresentam elementos gótico cômicos. Para compreender essa afirmação, propõe-se uma retomada sobre o gótico e sobre o humor, seguida de uma análise do subgênero em dois escritos do autor.

Não sendo muito conhecido no Brasil, Gorey tem apenas uma obra traduzida e publicada: A Bicicleta Epiplética. Além dessa, a dissertação de mestrado Uma tradução para "The Doubtful Guest" e "The Gashlycrumb Tinies", de Edward Gorey, concluída em 2015, propõe uma tradução comentada de duas de suas obras e a tese de doutorado "Traduzindo Amphigorey: uma antologia goreyesca", concluída em 2019, propõe uma tradução comentada para a primeira antologia do autor. Há, ainda, algumas pesquisas sobre Gorey com enfoque principalmente na literatura infantil e juvenil ou investigando características do gênero nonsense, tanto no texto verbal, quanto nas ilustrações, comparando-o a Edward Lear, autor vitoriano.

Seus livros têm cada vez mais atraído a atenção de fãs e de outros autores ou artistas que buscam inspirações em suas temáticas e ilustrações. Ainda que a fortuna crítica goreyesca não seja das mais extensas, a variedade de gêneros, temas e características que podem ser encontradas em seus livros instiga uma leitura mais crítica e observadora, despertando o interesse em explorar e desvendar suas peculiaridades.

Esta análise parte do pressuposto de que tanto o humor como o horror podem ser encontrados nas obras selecionadas, de forma que poderíamos contemplá-las como exemplos de obras gótico cômicas. Desse modo, busca-se compreender que elementos presentes nas obras comprovam tal afirmação ${ }^{2}$.

Para isso, serão retomados entendimentos sobre o humor com base em autores como Henri Bergson (1987) e Vladimir Propp (1992), atentando-se ao grotesco e à caricatura, meios pelos quais o horror pode ser aliviado, segundo Cross (2008). Propões também uma breve revisão sobre o gênero gótico, pautando-se principalmente em H. P. Lovecraft (1987), Fred Botting (2000), Neil Cornwell (2000). Em seguida, baseando-se em Avril Horner e Sue Zlosnik (2000) e em Julie Cross (2008), são tecidas considerações sobre o gótico cômico para, por fim,

\footnotetext{
${ }^{2}$ Na tese de Doutorado "Traduzindo Amphigorey: uma antologia goreyesca", há uma introdução sobre essas temáticas: humor, gótico e gótico cômico na obra de Edward Gorey. No entanto, tal introdução ocorre de forma ampla e generalizada, trazendo exemplos variados e tirados de outras obras de Gorey, não havendo uma análise aprofundada em nenhuma obra especificamente, tampouco explorando as obras aqui selecionadas.
} 
analisar as obras The Doubtful Guest e The Beastly Baby, com o intuito de identificar características góticas e características humorísticas.

The Doubtful Guest, publicada pela primeira vez em 1957, é um poema que narra a história de um monstrinho que aparece na casa de uma família e deliberadamente passa a viver e conviver com essa família. Uma das coisas que mais se destaca na história é o comportamento do monstrinho, que faz coisas esquisitas e parece quebrar com a rotina dos demais moradores. A outra obra, The Beastly Baby, publicada pela primeira vez em 1962, narra a história de uma criança com deformidades físicas e comportamento também peculiar, porém mais tenebroso que o primeiro. Ambas as obras são ilustradas em preto e branco pelo próprio autor.

Além de terem sidos publicadas isoladamente, as obras foram posteriormente incluídas em antologias. The Doubtful Guest foi incluída na primeira antologia publicada, intitulada Amphigorey, publicada pela primeira vez e The Beastly Baby foi incluída na segunda antologia publicada, intitulada Amphigorey Too.

A seleção dessas obras para esta análise ocorreu porque ambas trazem criaturas monstruosas e grotescas que têm comportamentos excêntricos, as ilustrações parecem mais sombrias do que realmente são ${ }^{3}$ e as cenas narradas são mais hilárias do que assustadoras. Evidentemente há outras obras do autor que poderiam ter sido selecionadas, o que de antemão evidencia que há espaço para outras discussões acerca do gótico cômico.

\section{Entre o riso e o horror}

Ainda que horror e riso pareçam antagônicos quando observados isoladamente, eles podem estar relacionados, sendo o gótico cômico um ponto de encontro, como apontam Horner e Zlosnik (2000). Os autores afirmam também que o gótico cômico tem recebido pouca atenção da crítica, sendo muitas vezes desprezado entre as escritas góticas exatamente pelo seu teor humorístico. Nota-se, com isso, que compreender essa variedade do gótico implica entender previamente o que provoca o riso. Portanto, uma breve retomada sobre as noções de humor e de gótico funciona como alicerce para compreender o gótico cômico.

Bergson (1983) defende que se ri daquilo que é humano, porém apenas na ausência de emoção. Aquilo que gera sentimento ou que desperta afeição não motiva o riso. Ri-se de

\footnotetext{
${ }^{3}$ As ilustrações não são apresentadas nesta pesquisa devido aos direitos autorais, já que as obras do autor ainda não estão em domínio público. No entanto, algumas imagens podem ser visualizadas no site http://www.goreyesque.com/gorey-images /, dedicado ao autor.
} 
deformidades ou defeitos, mas isso não quer dizer que toda deformidade ou defeito seja carregado de comicidade.

A manifestação do humor depende de fatores culturais, linguísticos e sociais. Determinada obra pode levar um público ao riso, e causar efeitos distintos a outros públicos. “Lá, onde um ri, outro não ri” (PROPP, 1992, p. 31), mas se há o riso, é porque a comicidade foi notada. Em se tratando de obras gótico cômicas, Cross (2008) defende que os leitores não são passivos, trabalham juntamente do texto para tirarem suas próprias conclusões. Se nesse processo riem, é porque assimilaram o efeito humorístico.

A ideia de que a comicidade esteja ligada àquilo que é humano é reforçada por Propp (1992) quando o autor afirma que tanto aspectos físicos quando aspectos intelectuais de um ser humano podem ser cômicos, como o rosto, a silhueta, os movimentos, a aparência de pouco senso comum, o caráter, a vida moral, as expressões verbais e até mesmo as não verbais.

Ambos os teóricos discorrem sobre os diferentes tipos de riso, afirmando que a natureza por si só não pode ser cômica, exceto se apresentar características humanas. Partes do corpo desproporcionais também tendem a levar ao riso, assim como fluídos corporais, como odores, desde que também não sejam consequências de doenças. O exagero, proveniente do que é caricatural, tende a ser risível. Contudo, para que se alcance a comicidade, não pode ser percebido (BERGSON, 1983).

No nível linguístico, o exagero também pode levar ao riso, como falar de coisas pequenas como se fossem grandes, a gabolice, as repetições, as imitações e as inversões, que levam à quebra de rigidez e de automatismo. Metáforas que são tomadas como literais, sentidos invertidos, ou que exprimem ideias distintas daquilo que é esperado, palavras e expressões com duplos sentidos, como trocadilhos e jogos de palavras, são exemplos mencionados por Bergson (1982). Outro elemento risível que merece destaque ao se pensar nas obras em estudo é a comicidade decorrente de movimentos e raciocínios, que pode ser refletida através de atitudes e comportamentos, com ações que extrapolam padrões sociais comumente aceitáveis, hábitos que causam estranheza ou atitudes que contradizem aquilo que é cotidiano.

Diversas personagens criadas por Edward Gorey levam o leitor ao riso, com peculiaridades variadas, que envolvem deformidades físicas, psicológicas e comportamentais, que causam estranhamento, porque são exagerados, acentuam defeitos e remetem ao grotesco, ou seja, “[...] aquilo que é aumentado já se transforma em monstruoso” (PROPP, 1992, p. 91), consequentemente, se aproxima ao gótico. No entanto, apesar da monstruosidade sugerida 
dialogar-se com o gótico, no caso de textos carregados de humor, dissipa-se o medo, que é "a emoção mais forte e mais antiga do homem [...]", segundo Lovecraft (1987, p. 10).

O medo é um dos sentimentos obtidos pelo leitor através dos textos góticos, o clima de mistério e fantasmagórico tornou-se importante para o desenvolvimento do gênero. Botting (2000) e Cornwell (2000) destacam os cenários góticos: castelos, ruínas, prisões, hospícios e monastérios, ambientes inóspitos, escuros ou úmidos, além dos eventos sobrenaturais. Eden Lee Lackner (2015) defende que o horror gótico é marcante na obra de Edward Gorey, com uma ampla ocorrência de cenários característicos e cenas sombrias ou escuras, reforçadas pelas ilustrações em preto e branco. Além disso, é notável a criação de monstros e seres sombrios nas histórias do autor, assim como cenas de violência ou de morte, ainda que nas entrelinhas, então aquilo que perturbaria o leitor se passa apenas “por trás das cenas” (WILKIN, 2009).

Com isso, as obras de Gorey não são assustadoras e não deixam o leitor com medo, as personagens são mais irritantes do que assustadores e levam o leitor mais ao riso do que ao horror. A violência e as ameaças, tanto nos textos verbais quanto nas ilustrações, por serem apenas sugeridas, se tornam "ambiguamente ameaçadoras"4 (ARLUKE, 2018, p. 94, tradução minha ${ }^{5}$ ), ou seja, não chocam, não perturbam, não causam medo ou assombro. Em resumo, não têm o efeito que se esperaria de uma obra gótica.

Enquanto o gótico está ligado à morte, ao medo e ao sobrenatural com a finalidade de assombrar, e desafia o leitor através de ameaças internas que tendem a serem influenciadas por questões histórias, sociais e culturais, o gótico cômico serve-se de tais elementos para divertir, intrigar e estimular o leitor, pois o "diabólico" resulta no riso e o excesso de grotesco gera humor (HORNER E ZLOSNIK, 2000; 2005). Isso não quer dizer que seja um riso despretensioso e sem propósito, as intenções críticas e as percepções culturais muitas vezes inerentes aos textos humorísticos podem estar incorporadas.

Cross (2008), ao investigar o gênero gótico em obras de literatura infantil e juvenil, argumenta que o humor de textos góticos depende de uma compreensão de ironia e de paródia, além de aquiescência em relação à incongruência, na qual o leitor percebe a diferença entre sua expectativa como leitor e a "realidade" daquilo que é expresso no texto. A quebra de expectativa é a "virada cômica" mencionada por Aranha (2008). Através dela o impacto das cenas violentas é diminuído. O humor nos livros de Gorey dependem dessa quebra de expectativa, que geram

\footnotetext{
${ }^{4}$ Ambiguously threatening

${ }^{5}$ Todas as traduções de citações em língua estrangeiras que não tragam tradutor nas referências, foram traduzidas por mim.
} 
distanciamento entre obra e leitor. A brevidade das narrativas, as rimas, os jogos linguísticos e sonoros e a ausência de detalhes nas histórias são características que colaboram para que se estabeleça esse distanciamento. Dessa forma, apesar das cenas impactantes, nas quais criaturas monstruosas têm comportamentos perturbantes, ou dos objetos e dos cenários convencionais do gótico, o leitor ri.

\section{Riso e horror em "The Doubtful Guest" e em "The Beastly Baby"}

A primeira obra, The Doubtful Guest, que será a partir de agora citada através da sigla $T D G$, é uma poesia narrativa, com 28 versos em tetrâmetros anapésticos, organizados em 14 dísticos com rimas emparelhadas. O livro é ilustrado pelo próprio autor e cada dístico traz uma ilustração que complementa o texto verbal. Resumidamente, o poema narra a história de um monstrinho, o "hóspede duvidoso", que chega inesperadamente na casa de uma família e decide com ela conviver.

Nessa história, nem o monstrinho e nem a família possuem nomes próprios, o hóspede é identificado pelo pronome $i t$, o que o distancia dos seres humanos, ao não ser identificado como "ele" (he) ou "ela" (she). O monstrinho, bastante peculiar, tem comportamentos esquisitos, que são narrados e reforçados pelas ilustrações, que cumprem um papel relevante para a percepção dos elementos góticos e humorísticos, pois, principalmente as características físicas ficam geralmente por conta das ilustrações.

A segunda obra, The Beastly Baby, que será a partir de agora citada através da sigla $T B B$, é assinada por um pseudônimo de Edward Gorey: Ogdred Weary, um anagrama do nome do autor. Essa narrativa prosaica também conta a história de um ser peculiar, todavia, neste caso, é um bebê caracterizado como animalesco, bestial, asqueroso (beastly). A narrativa traz diversas descrições físicas que são reforçadas pelas ilustrações, além de comportamentos e ações do bebê.

\subsection{Aspectos góticos nas obras}

Em ambas as obras são encontradas características góticas principalmente nas ilustrações, que são em preto e branco. As feições do monstrinho de TDG lembram um pinguim, mas ao mesmo tempo a ausência de detalhes não permite identificar o que ele é exatamente. Pode-se dizer que há deformidades físicas se compará-lo a outro ser, seja ele um animal ou um humano. Já suas ações aproximam-se das capacidades cognitivas humanas. O "hóspede 
duvidoso" é aqui compreendido como um tipo de monstro exatamente pelo fato de não ser possível identificá-lo como humano ou animal, é como uma figura híbrida, não sendo um, nem outro, mas tendo um pouco dos dois.

Outras características góticas encontradas nesta obra são os cenários e imagens escuras. A primeira ilustração traz um vaso ornamental sobre uma cerca, aparentemente de pedra ou cimento, em uma casa antiga. Nas ilustrações seguintes, é possível notar um pátio amplo e uma parede da casa, de tijolos, alta, como se fosse um castelo ou casarão, embora a ilustração não permita visualizá-los por completo. Paredões são comuns no horror gótico, dando a impressão de um local escuro e úmido. A decoração da casa, com paredões, cortinas e papéis de parede escuros, quadros, bustos ${ }^{6}$, lareiras, escadas de madeira e planos de fundo pretos reforçam a ambientação gótica. Além disso, a seriedade e as vestimentas das outras personagens também remetem ao macabro, com olhar sempre escuro e sombrio, como se tivessem olheiras profundas, o que traz certa morbidade, além de feições sérias e carrancudas, irritadas, quase sempre encarando o monstrinho.

O texto verbal informa que o monstrinho chegou em uma noite de inverno severo em que os habitantes não esperavam ninguém. Quando notaram uma coisa em pé sobre o vaso decorativo, era o "hóspede”. Em seguida, é possível notar as primeiras impressões que a família, identificada apenas pelo pronome "eles" (they), tem em relação ao monstrinho, identificado por "isso, a coisa, uma coisa" (it, something). A primeira impressão do monstro narra que ele era peculiar e com uma aparência que causava tontura. No decorrer da história, narra-se que ele parecia ser surdo para o que lhes diziam e que era sonâmbulo, pois durante à noite se arrastava sem rumo pela casa enquanto dormia. Tais impressões e comportamentos também reforçam a ambientação gótica.

Em $T B B$, similarmente, as cenas são escuras, mas as ilustrações são menos detalhadas do que em $T D G$, há mais rabiscos e contornos menos definidos, além de ilustrações sem planos de fundo. As primeiras ilustrações trazem apenas o bebê em diferentes posições. A primeira ilustração, na qual há apenas o título e o anagrama com nome do autor, o bebê está segurando uma adaga, seus olhos são rabiscos pretos, como olheiras, similarmente aos personagens de $T D G$. Outros elementos que reforçam a ambientação gótica nas ilustrações são o carrinho de bebê, bastante antigo, de ferro, comum em filmes de terror, as feições do bebê, seu corpo feio e desproporcional, as outras personagens, também com contornos não muito definidos e sem

\footnotetext{
${ }^{6}$ Bustos, neste caso, são as esculturas com peito e cabeça de uma pessoa, sem braços.
} 
detalhes nos rostos, majoritariamente com sombras escuras, um gato decapitado pelo bebê, um pequeno busto sobre a mesa sendo quebrado e um penhasco; elementos recorrentes no gótico.

Por si só, o bebê é um bom exemplo de personagem gótica, pois suas feições são horríveis, principalmente por se tratar de um bebê. As descrições são reforçadas pelo texto verbal, que também utiliza o pronome it para se referir à protagonista, em vez de he ou she, como seria esperado. A escolha do pronome it aproxima o bebê a um animal, uma coisa, um outro tipo de ser, tirando seu caráter humano. Isso é reforçado quando se utiliza o pronome he para se referir à águia que aparece no final da história, ou seja, há uma inversão no que tange a representação dos seres, o bebê é animalizado enquanto a águia é humanizada.

A explicação do texto verbal traz para o fato de o bebê não ter um nome é que ninguém se importava em falar sobre isso. Há uma ambiguidade neste trecho (It had never been given a name since no-one cared to talk about it), o it no final da frase poderia tanto se referir ao bebê quanto a assunto (falar sobre o bebê ou falar sobre esse assunto). A primeira interpretação (it= bebê) reforça a animalização do bebê, enquanto a segunda (it = assunto), reforça a insignificância que o bebê tem para sua família, que não se importou nem mesmo em escolher um nome para ele. A ambiguidade não é resolvida, mas o resultado da indiferença dá origem ao que seria o apelido da protagonista: Beastly Baby, é assim que o chamam, quando necessário.

Além disso, o texto verbal reforça a aparência e o comportamento asqueroso do bebê. Narra-se que ele era pior que outros bebês, pois era maior, seu corpo era redondo, inchado, um de seus pés tinha muitos dedos, enquanto faltavam dedos nos outros, ambas as suas mãos eram canhotas, seu nariz era pontudo e parecia ser mais velho que o restante do corpo, os olhos eram pequenos e escuros por causa das olheiras, era úmido e grudento de tanto que chorava, fazia barulhos horríveis e não conseguia andar. Poucas ilustrações mostram o rosto do bebê, mas nas quais é apresentado, nota-se uma feição bastante horrenda, ora provocante e maléfica, ora desolada.

Suas ações também colaboram para que o gótico se estabeleça, conforme a história o bebê quase não dorme por ter a consciência pesada, chora ao ter autocomiseração e faz dois tipos de barulhos horríveis, o primeiro é um "murmúrio engasgado", que lembra um ralo com defeito, esse barulho é emitido quando o bebê é bem sucedido em alguma atrocidade, já o segundo é um grito agudo e fino, como se fossem unhas arranhando um quadro negro, esse barulho é emitido quando não permitem que ele faça uma atrocidade. Outros comportamentos do bebê são: rasgar o carpete com objetos cortantes, fazer buracos com ácido e atirar nas decorações sobre as mesas. 
Contudo, não é apenas o bebê que tem um comportamento horrendo na história, as atitudes das outras personagens em relação ao bebê também são boas representações do gótico. Objetos letais eram entregues ao bebê com o intuito de que ele se machucasse mortalmente, ele foi deixado sob o sol, onde queimou-se até ficar horrivelmente roxo, nos lugares públicos, outras pessoas temiam que ele fosse "deixado para trás", o fato de ele crescer e ficar mais velho gerava desconforto, e quando foi levado a um piquenique colocaram-no na beira de um precipício, por onde uma águia passou e o levou embora.

Em resumo, notam-se diversas referências ao horror, que Carroll (1999) define como sendo algo repugnante, como lugares lamacentos, animais nocivos, coisas rastejantes, monstros que são mostrados e não apenas descritos, que despertam no leitor não apenas medo, mas também nojo ou repulsa. Apesar disso, nenhuma das histórias causa medo, o leitor não se sente perturbado. Isso ocorre porque os elementos desagradáveis são postos com indiferença (Wilkin 2009), consequentemente, em vez de medo, tais obras levam o leitor ao riso, o que motiva a investigação de elementos humorísticos na obra.

\subsection{Aspectos humorísticos nas obras}

Conforme comentado anteriormente, ri-se daquilo que é humano, de exageros, daquilo que extrapola o senso comum, de deformidades e de defeitos, desde que não oriundos de doenças e, para que o riso ocorra, é necessário que haja um distanciamento entre a obra e o leitor.

Em $T D G$, o hóspede, ainda que em sua peculiaridade, assemelha-se a humanos, sendo essa uma de suas características cômicas. Primeiramente, por suas vestimentas, um cachecol listrado e tênis brancos, dois itens que comumente são utilizados por Edward Gorey e que trazem uma modernidade que se contrasta às vestimentas das outras personagens, mais tradicionais. Os itens de vestuário do monstrinho trazem comicidade porque dão um toque informal, infantil e moderno em um ambiente misterioso, escuro e vitoriano.

Outro elemento risível é o comportamento do monstrinho. Primeiramente ele é visto sobre o vaso decorativo, um local inusitado, em seguida corre para dentro do corredor. $\mathrm{O}$ hóspede não é um convidado, mas um intruso que adentra a propriedade, onde fica em pé com o nariz na parede, não ouve nem dá atenção aos gritos que lhe são direcionados, que se junta para o café da manhã, senta-se à mesa e come o todo o xarope de bordo (maple syrup), a torrada e, surpreendentemente, uma parte do prato. Entre outras ações, o monstrinho arranca capítulos de livros, deita-se no chão inconvenientemente, bloqueando a entrada, esconde-se numa sopeira 
e esconde também as toalhas de banho. Todos esses comportamentos extrapolam padrões de comportamento e por isso se tornam cômicos.

As ilustrações reforçam a comicidade. Embora sejam em preto e branco e escuras, complementam o texto verbal oferendo mais detalhes à narrativa. Seus olhos brancos, redondos e arregalados se destacam na cabeça longa e peluda como seu corpo. Assim, há a impressão de que o monstrinho é inocente em suas ações, aquilo que faz, faz por fazer, não para provocar ou irritar, mas porque aquele comportamento parece ser natural para ele, o que também evoca o riso.

As outras personagens parecem incomodadas, mas não assustadas. Numa história de horror, um monstro que invadisse uma casa e nunca mais fosse embora causaria medo, no gótico cômico, esse monstro causa irritação em outras personagens e riso ao leitor. A narrativa curta, sem muitos detalhes ou respostas, em versos, com ritmo regular e rimas emparelhadas colabora para o distanciamento entre leitor e texto, consequentemente, colabora também para suscitar humor.

Isso é semelhante em $T B B$, o bebê quebra com as expectativas do leitor e das outras personagens. Por se tratar de um bebê, a quem geralmente são dirigidos adjetivos amáveis, o leitor certamente não esperaria algo horrendo ou disforme. Quebrando tal expectativa, o leitor depara-se com uma aberração monstruosa, não apenas na aparência, mas também no comportamento. A expectativa das outras personagens, que dão objetos letais para o bebê esperando que ele se machuque, também é quebrada, pois o bebê não se machuca. Em vez disso, utiliza tais objetos para destruir o que está próximo dele, contrariando e irritando as outras personagens enquanto diverte o leitor.

O bebê tem olheiras e quase nunca dorme por ter a consciência pesada, além de chorar de autocomiseração, dois sentimentos nada comuns para um bebê, o que certamente causa estranheza e surpresa para o leitor. A ideia angelical que geralmente se constrói quando se pensa em um bebê é contrariada de diversas formas. $\mathrm{O}$ fato de um bebê crescer e aprender a andar geraria alegria e expectativa aos familiares, porém, nessa narrativa, o fato de não conseguir andar gera alívio, e pensar que ele pode crescer, gera medo, por não saberem em que se transformará.

Esquecer o bebê em um local público certamente geraria ansiedade e nervosismo para os pais, neste caso, a ansiedade e o nervosismo ocorrem nos oficiais que cuidam do local público, que temem que aquele bebê seja esquecido. Por fim, ir a um piquenique é uma atividade alegre, geralmente em um local bonito e agradável, no entanto, nessa história, 
representa o fim do bebê, pois ele é colocado na beira de um precipício, distante da comida, de onde é levado por uma águia, gerando alegria nas outras personagens. A morte ocorre nas entrelinhas, comum nas obras de Gorey, deduz-se que o bebê morre, porque na última ilustração é possível observá-lo representado através de um ponto pequeno caindo do céu, no canto inferior direito.

Seria uma história terrível, se não fosse fonte de riso e comicidade. Novamente, a brevidade da narrativa e a ausência de detalhes têm um papel importante para distanciar o leitor e permitir que o humor se estabeleça.

\section{Considerações finais}

O gótico cômico, como uma subdivisão do gótico, une horror e humor. Nas duas obras em estudo, características do horror se dão principalmente nos cenários escuros e cheios de elementos comuns nas histórias góticas, com as ilustrações em preto e branco que, segundo McGlothling (2013), são importantes para criar os ambientes e as personagens. Além disso, as ações das personagens reforçam as cenas de horror, principalmente em $T B B$, com os comportamentos desagradáveis do bebê e das outras personagens em relação a ele.

Os protagonistas de ambas as obras são exemplares de monstros. O hóspede de TDG é uma criatura monstruosa, que se assemelha a um animal em sua aparência, mas a um humano em suas ações e vestimentas. O bebê de $T B B$ é um humano que se parece mais com uma criatura monstruosa, afastando-se de suas características humanas e infantis devido às deformidades físicas, à aparência e aos seus comportamentos. Ambas as criaturas são representadas pelo pronome it, o que as descaracteriza como humanas, ambas são grotescas e exageradas, embrenhando-se com o fantástico e o caricatural.

Como se pôde notar, o riso surge porque as deformidades destacadas não causam medo nem empatia e porque os elementos humorísticos nas obras ocorrem com a quebra de expectativa das ações que supostamente seriam horríveis. Os comportamentos esquisitos quebram os padrões sociais, contrariam o que é habitual e cotidiano, por isso causam estranheza. No entanto, tais comportamentos parecem naturais, nenhuma das obras intenta forçar o riso no leitor, sendo este um elemento importante para o humor. Os textos verbais curtos, com efeitos sonoros e rítmicos, como em TDG, mas sem detalhes minuciosos, colaboram para que o humor ocorra, também porque contribuem com o distanciamento do leitor. 
Assim, monstros que não assustam, mas levam o leitor ao riso, que têm comportamentos excêntricos, alguns até horrendos, mas que não despertam medo, que irritam as outras personagens da narrativa, mas não as assustam, causando divertimento ao leitor e deixando-o intrigado, talvez perplexo, são bons representantes do gótico cômico.

\section{REFERÊNCIAS}

ARANHA, Renato M. Gótico em quadrinhos: entre o humor e o terror em A piada mortal. In: O humor nas literaturas de expressão de língua inglesa. Suellen Cordovil da Silva \& Tiago marques Luiz (org.). Jundiaí: Paco, 2018. p. 131-149.

ARLUKE, Arnold. Understanding Gorey's Human-Animal World. In: Erin Monroe (org.). Gorey's Worlds. Hartford, Connecticut: Wadsworth Atheneum Museum of Art in association with Princeton University Press, 2018. p. 77-99.

BERGSON, Henri. Para compreender o riso: Ensaio sobre a significação do cômico. Tradução de Nathanael C. Caixeiro. $2^{a}$ ed. Rio de Janeiro: Zahar Editores S. A., 1983. Disponível em: < https://pdfslide.tips/documents/bergson-henri-o-risopdf.html> Acesso em 12 jul. 2020.

BLOOM, Clive. Horror Fiction: In Search of a Definition. In: A companion to the Gothic. David Punter (ed.). Oxford: Blackwell Publishers, 2000. p. 155-166.

BOTTING, Fred. In Gothic Darkly: Heterotopia, History, Culture - Fred Botting. In: A companion to the Gothic. David Punter (ed.). Oxford: Blackwell Publishers, 2000. p. 3-14.

CARROLL, Nöel. A filosofia do Horror ou Paradoxos do Coração. Tradução de Roberto Leal Ferreira. Campinas: Papirus, 1999. p. 13-91.

CORNWELL, Neil. European Gothic. In: A companion to the Gothic. David Punter (ed.). Oxford: Blackwell Publishers, 2000.

CROSS, Julie. Frightening and Funny: Humour in Children's Gothic Fiction. In: JACKSON, A.; COATS, K; McGILLIS, R (Org.). The Gothic in Children's Literature: Haunting the Borders. New York: Routledge, Taylor \& Francis Group, 2008. P. 57-76.

GOREY, Edward. The Beastly Baby. In: Amphigorey Too. New York: Penguim Books, 1975.

GOREY, Edward. The Doubtful Guest. In: Amphigorey. New York: Perigee Books, 1972.

GOREYESQUE. Illustrations. Disponível em: http://www.goreyesque.com/gorey-images. Acesso em: 20 nov. 2020.

HORNER, Avril; ZLOSNIK, Sue. Comic Gothic. In: A companion to the Gothic. David 
Punter (ed.). Oxford: Blackwell Publishers, 2000. p. 242-254.

Horner A., Zlosnik S. Topography and the Comic Gothic Turn. In: Gothic and the Comic Turn. Londres: Palgrave Macmillan, 2005. Disponível em: https://link.springer.com/chapter/10.1057/9780230503076_5\#citeas. Acesso em 20 nov. 2020.

LACKNER, Eden Lee. Genre Games: Edward Gorey's play with generic form. [Tese]

Doutorado em Filosofia. Victoria University of Wellington, 2015. Disponível em:

<http://researcharchive.vuw.ac.nz/xmlui/handle/10063/4671> Acesso em ago. 2020.

LOVECRAFT, H. P. O Horror Sobrenatural na Literatura. Tradução de: João Guilherme Linke. Rio de Janeiro: Livraria Francisco Alves Editora, 1987.

MCGLOTHLING, Kristin L. Edward Gorey's illustrations of misshapen children. Faculty of the Dorothy F. Thesis (Master of Arts). Florida Atlantic University, 2013. Disponível em: <http://fau.digital.flvc.org/islandora/object/fau\%3A4120>. Acesso em ago. 2020.

MICOANSKI, Angelica. Uma tradução para The Doubtful Guest e The Gashlycrumb Tinies, de Edward Gorey. Dissertação (Mestrado em Estudos da Tradução). Universidade Federal de Santa Catarina, Florianópolis/SC, 2015. Disponível em: <https://repositorio.ufsc.br/handle/123456789/169298>. Acesso em ago. 2020.

PROPP, Vladimir. Comicidade e Riso. Tradução de Aurora Fornoni Bernardini e Homero Freitas de Andrade. São Paulo: Editora Ática, 1992.

THOMAZINE, Angelica M. Traduzindo Amphigorey: uma antologia goreyesca. Tese (Doutorado em Estudos da Tradução). Universidade Federal de Santa Catarina, Florianpólis/SC, 2019.

Watt, James. Contesting the Gothic: Fiction, Genre and Cultural Conflict, 1764-1832 (Cambridge Studies in Romanticism). Cambridge: Cambridge University Press, 1999. [2020]. [Kindle Android version]. Retrieved from Amazon.com.

WILKIN, Karen. Ascending Peculiarity: Edward Gorey on Edward Gorey. Orlando: Harcourt, 2001.

Recebido em 30/8/2020.

Aceito em 07/12/2020. 